IZA DP No. 8329

Migration Policy, African Population Growth and Global Inequality

Andrew Mountford

Hillel Rapoport

July 2014 


\title{
Migration Policy, African Population Growth and Global Inequality
}

\author{
Andrew Mountford \\ Royal Holloway, University of London \\ Hillel Rapoport \\ PSE, University Paris 1 Pantheon-Sorbonne, \\ Bar-Ilan University and IZA
}
Discussion Paper No. 8329
July 2014

IZA
P.O. Box 7240
53072 Bonn
Germany

Phone: +49-228-3894-0

Fax: +49-228-3894-180

E-mail: iza@iza.org

Any opinions expressed here are those of the author(s) and not those of IZA. Research published in this series may include views on policy, but the institute itself takes no institutional policy positions. The IZA research network is committed to the IZA Guiding Principles of Research Integrity.

The Institute for the Study of Labor (IZA) in Bonn is a local and virtual international research center and a place of communication between science, politics and business. IZA is an independent nonprofit organization supported by Deutsche Post Foundation. The center is associated with the University of Bonn and offers a stimulating research environment through its international network, workshops and conferences, data service, project support, research visits and doctoral program. IZA engages in (i) original and internationally competitive research in all fields of labor economics, (ii) development of policy concepts, and (iii) dissemination of research results and concepts to the interested public.

IZA Discussion Papers often represent preliminary work and are circulated to encourage discussion. Citation of such a paper should account for its provisional character. A revised version may be available directly from the author. 
IZA Discussion Paper No. 8329

July 2014

\section{ABSTRACT \\ Migration Policy, African Population Growth and Global Inequality}

According to recent UN projections more than 50 percent of the growth in world population over the next half century will be due to population growth in Africa. Given this, any policy that influences African demography will have a significant impact on the world distribution of income. In this paper we discuss the potential for migration policies to affect fertility and education decisions, and hence, population growth in Africa. We present the results from different scenarios for more or less restrictive/selective migration policies and derive their implications for the evolution of world inequality.

JEL Classification: $\quad$ O40, F11, F43

Keywords: $\quad$ global inequality, migration, fertility, Africa

Corresponding author:

Hillel Rapoport

Centre d'Economie de la Sorbonne

Paris School of Economics

106-112 Bd. De l'Hôpital

75013 Paris

France

E-mail: hillel.rapoport@psemail.eu

\footnotetext{
* We thank participants and the organisers of the international conference on "International labor mobility and inequality across nations" in Clermont-Ferrand (France), January 2014. We are grateful to our discussant at the conference, Jesús Fernández Huertas Moraga for very useful comments and suggestions. We also thank Blandine Vachon for excellent research assistance. All remaining errors are our own. Hillel Rapoport acknowledges support from CEPREMAP.
} 
In the next 10 years, there will be more than 100 million more school-aged children in Africa. By the year 2050, more than a quarter of the world workforce will be African. And in the next three generations, more than 40 percent of the entire world youth will live in Africa. This is not just a challenge. This is an extraordinary opportunity, not just for Africans but for the world.

Secretary of State John Kerry, May 25th 2013, African Union 50th Anniversary Summit.

\section{Introduction}

In his address to the African Union on the occasion of its 50th anniversary, Secretary of State John Kerry was referring to the recently released United Nations Population Division forecasts for the next century. The UN is now projecting that the world population will keep growing throughout the rest of the century and will reach nearly 11 billion by the year 2100. These figures differ markedly from their previous projections released four years ago and which showed a milder increase. In any event, such projections necessarily rely on a number of assumptions that are by nature disputable and that have been widely criticized recently. For example, Deutsche Bank economist Sanjeev Sanyal suggested that population growth for Africa was largely over-estimated due to a few but critical assumptions, notably the assumption of a stable long-run level of population (New York Times, 2013a).

A general critique that can be addressed to demographic projections, and to UN projections in particular, is that they tend to neglect the potential for economic forces to shape demography. Typically, demographic projections do not anticipate that economic forces can bring about major policy changes that, in turn, affect the micro decisions of household when they choose the number and education level of their children. A striking illustration of this is the recent relaxation of the one-child policy in China in response to age and gender imbalances in the population that were judged by China's authorities as compromising the country's growth and development prospects (New York Times, 2013b). Such sudden policy changes will undoubtedly impact on the fertility, age structure and eventually the population size of China; given that China is one of the largest countries of the world in terms of demographic size, whatever affects demography 
in China has important repercussions for the distribution of the world population and, hence, on the world distribution of income. The same applies to African demography. Policy changes that affect African population growth will significantly impact global inequality.

The UN projections are widely used by governments and international agencies to design global policies addressing important issues such as global warming, food security, energy security, as well as, of course, political and economic imbalances. Our point, however, is not to propose another estimate of the world population growth for the coming decades but to demonstrate the potential sensitivity of such figures to changing policy environments. The policy we are interested in is migration, that is, whether immigration policies in the advanced economies will become more or less restrictive (determining how many people are allowed to move legally from developing to developed countries) and whether they will become more or less selective (that is, favor the highly educated and skilled, which will determine the skill composition of migration flows and the induced effects in terms of quality-quantity trade off for children, as described in the next section). Indeed, the UN projections (and, for that purpose, virtually all demographic projections released by international agencies) neglect the fact that migration is affecting the size and composition of nations ipso facto (i.e., directly, by moving people) but also indirectly, through the interaction between migration and other households decisions regarding human capital investment and fertility.

Migration can affect fertility through a number of channels, first and foremost by affecting the expected return to human capital and, hence, via the qualityquantity trade-off for children, see Docquier and Rapoport (2012), for a review of this literature. This is the channel that we focus on in this paper but there are other potential channels, such as e.g. remittances. Recent work has also emphasized a transmission of norms mechanism, whereby migrants transfer social norms regarding fertility behavior from destination to home. This transmission mechanism has first been suggested by Fargues (2007) to explain why high-emigration regions of Morocco have lower than average fertility while high-emigration regions of Egypt have higher than average fertility; the hypothesis being that in both cases migrants remit the type of fertility behavior they experience wherever they live (that is, low-fertility for Moroccan migrants in Western Europe and high-fertility for Egyptian migrants in the Gulf). This conjecture has been confirmed for Egypt by Bertoli and Marchetta (forthcoming) and in cross-country comparisons by Beine, Docquier and Schiff (2013), who also find evidence for the 


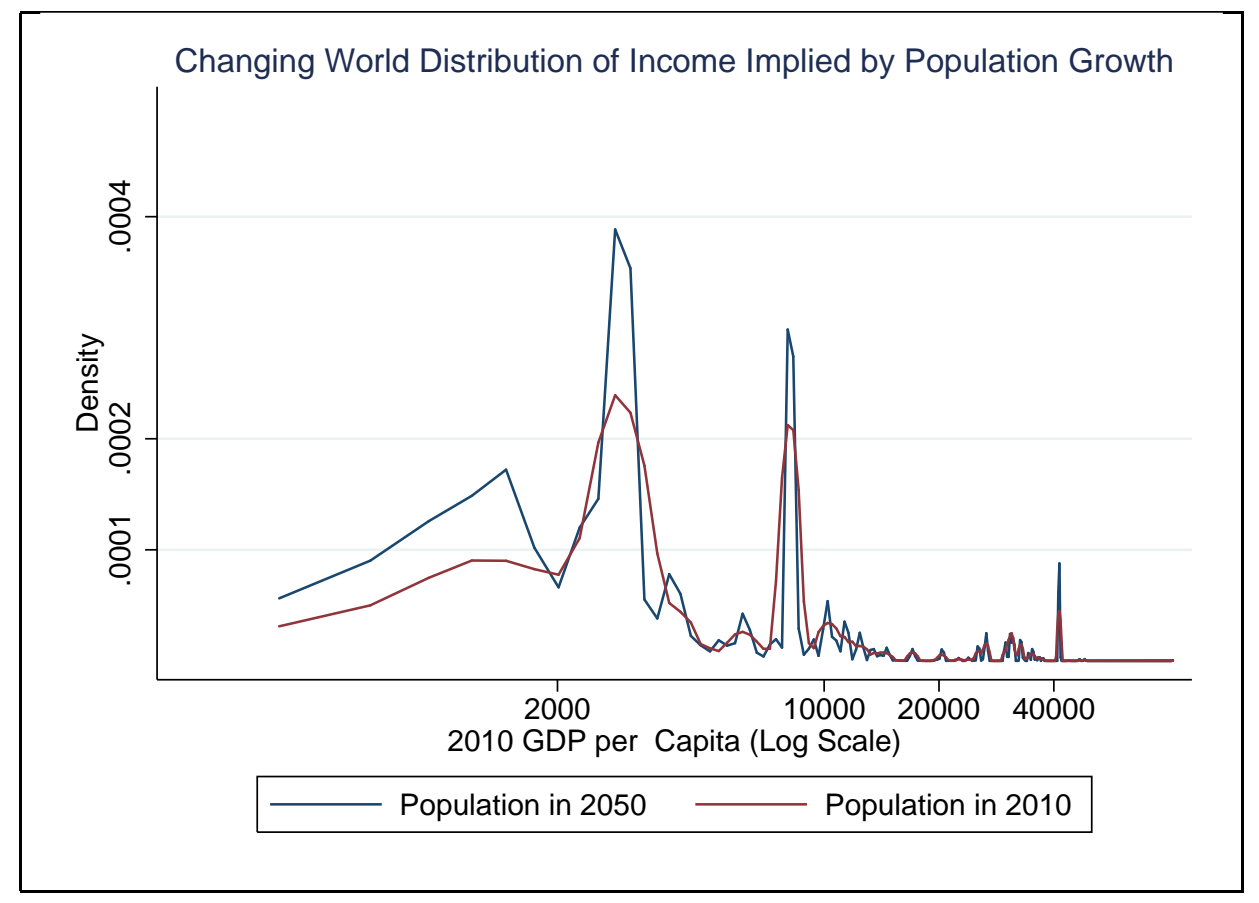

Figure 1: The density of log GDP per capita in the world economy holding GDP per capita constant at 2010 levels while changing the distribution of world population to that of the UN estimates in 2010 and 2050.

other channels. Using data on internal migration in 19th century France, Daudin, Franck and Rapoport (2013) further suggest that such cultural diffusion channel played a significant role in explaining the transmission of the fertility transition.

This paper emphasizes the quantity-quality trade-off framework in which decisions about the number of children to raise, and how much education to give them, is affected by the global demand for skills (which determines wage premiums and inter-country wage differentials) and by the policies allowing for labor to move across borders (i.e., the extent to which workers in the South can respond to changes in the demand for skills in the North). The quantity-quality trade-off has been shown to be an important factor in explaining the demographic transition from the Malthusian to the Modern Growth regime in the 19th century (see Galor, 2005). It is therefore natural to ask whether the changes in the demand for skills will have significant effects on the fertility path of today's developing countries in the 21 st century.

The paper which is most closely related to ours is a recent paper by Delogu, 


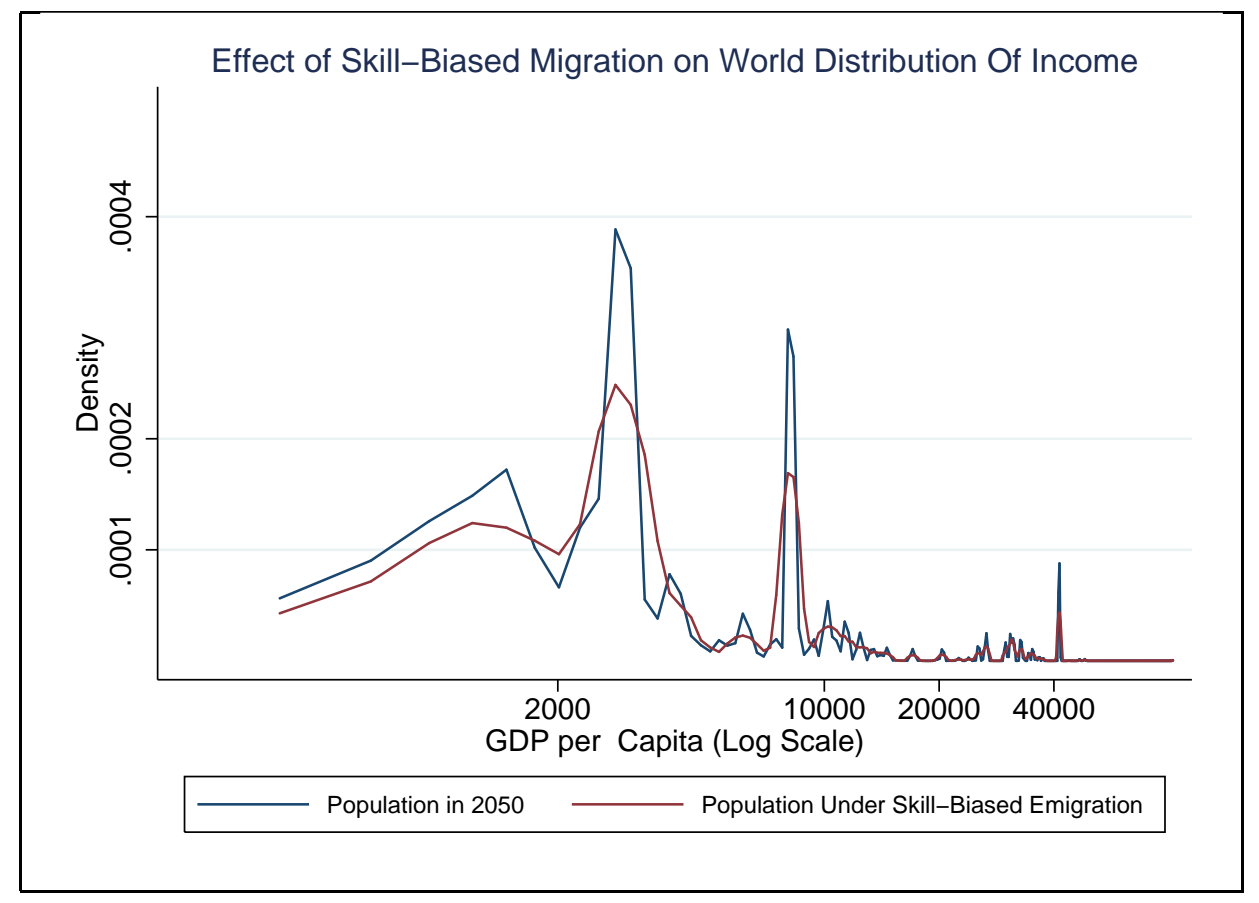

Figure 2: The density of log GDP per capita in the world economy in 2050 under the UN projected population and under a scenario of skill biased emigration from Africa.

Docquier and Machedo (henceforth DDM) (2013). We view our paper as a complement to their study in that it addresses the same topic but from a different angle and using alternative underlying assumptions. In particular, the migration scenarios retained differ. DDM (2013) assume a full liberalization of the movement of labor (i.e., all individuals willing to emigrate - according to the Gallup survey - are free to do so) and so migration is modelled as an optimal location choice where migration costs play a central role. In contrast in our model emigration remains largely constrained and we assume there to be an excess supply of South-North migrants and focus on the way changing emigration propensities affects the quality-quantity trade-off for children and, thus, the relative size of nations. We model immigration policy in two dimensions: the total degree of openness and the degree to which immigration is selective (i.e., the degree to which there is a differential probability of emigration across skill groups). Finally, our model is also a much simpler one highlighting the contribution of the quantity-quality trade off to population change in the next half-century or so and emphasizing the interaction between migration and this trade-off, while DDM are focusing on inter-country and within-country wage gaps.

The evolution of the African population will clearly have a direct effect on the evolution of world income inequality. Figure 1 illustrates the effect of the projected changes in world population on the world distribution of income by 
plotting the density of the world distribution of income under the UN's medium variant population estimates for 2010 and 2050 while holding each countries' GDP per capita constant at their 2010 levels. The figure shows that according to the UN projections, the populations of poorer countries will be growing relatively to richer countries in the next half century and that this ceteris paribus will tend to increase world inequality by increasing the density of the distribution at low income levels and decreasing it at higher income levels. However, as we argue in this paper, all things are not equal. The evolution of the world population distribution, and so of the world distribution of income, will be significantly affected by changing economic incentives in the world economy over the next half century.

There are many potential candidates for economic changes, including changes in economic policies, that may influence demography over the next few decades. One obvious candidate is a direct policy change with respect to fertility, as we have seen in the case of China. However there also many other possible indirect influences such as technological change or health shocks for example. We focus on one such potential change, migration policy. Over the last quarter of a century, immigration policies in most OECD economies have become quantitatively more restrictive and qualitatively more selective (see Bertoli and Rapoport (2013)). Mountford and Rapoport (2011) derive the theoretical implications of these changes, especially the fact that international migration is increasingly becoming of the "Brain Drain" type, for the world distribution of population and for world inequality.

We find that changes in immigration policies in destination countries can have significant effects on demographic and economic outcomes. Figure 2 illustrates this point. This figure compares the world distribution of income implied by the UN medium variant population projection in 2050 - again holding GDP per capita constant at 2010 levels - with that of a scenario where emigration possibilities from Africa become increasingly skill-biased as described in section 4.1 below. Differential emigration probabilities in favor of the highly educated and skilled increase the incentives to reduce fertility and invest in education, thereby reducing African population growth. As Figure 2 shows this results in a less unequal world distribution of income than the UN projection, reversing in part the increase in world inequality implied by demographic changes as projected by the UN.

\section{Theoretical Framework}

In this section we describe briefly the model underlying the simulations in sections 3 and 4. The model is an extension of the overlapping generations model of Mountford and Rapoport (2011). In each period $t$, output $Y_{t}$ may be produced 
using two factors of production, skilled labor, $H_{t}$, and unskilled labor $L_{t}$, under perfect competition, where the levels of $H_{t}$ and $L_{t}$ are determined endogenously by the optimal decisions of agents. Agents live for two periods and are endowed with one unit of labor in their second period. Agents are identical in all respects except for their level of ability, $a$, which we will assume is distributed normally over the unit interval, i.e. as a truncated normal distribution, and independently of the ability level of their parent. If the agent becomes skilled, then agent $i$ can supply $g_{t}+a_{i}$ efficiency units of skilled labor, where $g_{t}$ is the annual rate of growth of technology. Otherwise the agent remains unskilled and supplies one efficiency unit of unskilled labor. This implies that an increase in the rate of technological progress will increase the number of efficiency units a skilled worker supplies and will ceteris paribus increase the relative wage of skilled workers, as in Galor and Moav (2000) and Gould, Moav and Weinberg (2001). The level of technology, $A_{t}$, in each period is given and technological progress from one period to the next is related to the level of human capital accumulation in the economy and so is also determined endogenously.

The production function is a constant returns to scale Cobb-Douglas and so in each period output is given by the following expression

$$
Y_{t}=A_{t} H_{t}^{\alpha} L_{t}^{1-\alpha}
$$

where $H_{t}$ and $L_{t}$ are the levels of skilled and unskilled labor in the economy.

Defining $h_{t} \equiv H_{t} / L_{t}$, factor prices for each factor are given by their marginal products and hence

$$
w_{t}^{H}=\alpha A_{t} h_{t}^{\alpha-1} ; \quad w_{t}^{L}=(1-\alpha) A_{t} h_{t}^{\alpha}
$$

Thus we can write

$$
\frac{w_{t}^{L}}{w_{t}^{H}}=\frac{(1-\alpha)}{\alpha} h_{t}
$$

and in the absence of migration therefore from our distributional assumptions,

$$
h_{t}=\frac{\int_{a_{t}^{\star}}^{1} f\left(\mu\left(g_{t+1}\right), \sigma^{2}\right) d i}{a^{*}}
$$

where $a^{*}$ is the critical level of ability below which agents remain unskilled at period $t$ and $f\left(\mu\left(g_{t+1}\right), \sigma^{2}\right)$ is the probability density function of efficiency units of labor which is integrated over the different levels of ability of high skilled workers.

\subsection{Individuals' Preferences and Budget Constraints}

In their first period of life individuals are dependent on their parent who decides whether or not they become skilled. As described above, skilled individuals can 
supply $g_{t}+a_{i}$ efficiency units of skilled labor while those remaining unskilled can supply only one efficiency unit of unskilled labor.

Individuals make optimal decisions over fertility, consumption and the training of their offspring, with the preferences of a member of generation $t$ (i.e., an individual who is born in period $t-1$ ) defined over their consumption in period $t, c_{t}$, and the total income of their offspring, $d_{t+1}$, and are represented by the utility function.

$$
u_{t}=c_{t}^{\theta} d_{t+1}^{1-\theta}
$$

Individuals are assumed to be 'small' and so take the wage rate and growth rate in periods $t$ and $t+1$ as given. Individuals optimally allocate their time between labor force participation and child rearing. Denoting the time required to bring up skilled offspring as, $\tau^{s}$, and the time required to bring up unskilled offspring as, $\tau^{u}$, where we assume that $0<\tau^{u}<\tau^{s}<1$, the budget constraint of a member $i$ of generation $t$, is

$$
c_{t}+w_{t}^{i}\left(\tau^{s} n_{t}^{H}+\tau^{u} n_{t}^{L}\right) \leq w_{t}^{i} \text { for } i=s, u
$$

where $n_{t}^{H}$ and $n_{t}^{L}$ are measures of skilled and unskilled offspring respectively.

\subsection{Emigration}

We will analyze the effects of permanent emigration on the sending economy. We assume that the gap in TFP between the developed world and the less developed world is great enough that it is always the case that more agents would like to emigrate than are able. We consider both skilled and unskilled emigration and assume that the probability of emigration differs across skill. We denote the probability of emigration for a skilled worker as $\pi^{s}$ and that for an unskilled worker as $\pi^{u}$. We assume that probability of emigration is not affected by the level of ability but is only affected by the skill level. Intuitively the loss of emigrating skilled agents will ceteris paribus reduce the level $h_{t}$ and that loss of unskilled agents will ceteris paribus raise the level $h_{t}$ but the possibility of emigration will also increase the incentive to accumulate human capital and so the equilibrium effect may differ from this intuition, see Mountford and Rapoport (2011) and earlier literature on the brain drain (e.g., Mountford (1997), Beine, Docquier and Rapoport(2001,2008) and Kanbur and Rapoport (2005)). With these emigration probabilities the expression for $h_{t}$ becomes

$$
h_{t}=\frac{\left(1-\pi^{s}\right) \int_{a_{t}^{\star}}^{1} f\left(\mu\left(g_{t+1}\right), \sigma^{2}\right) d i}{a^{*}\left(1-\pi^{u}\right)}
$$




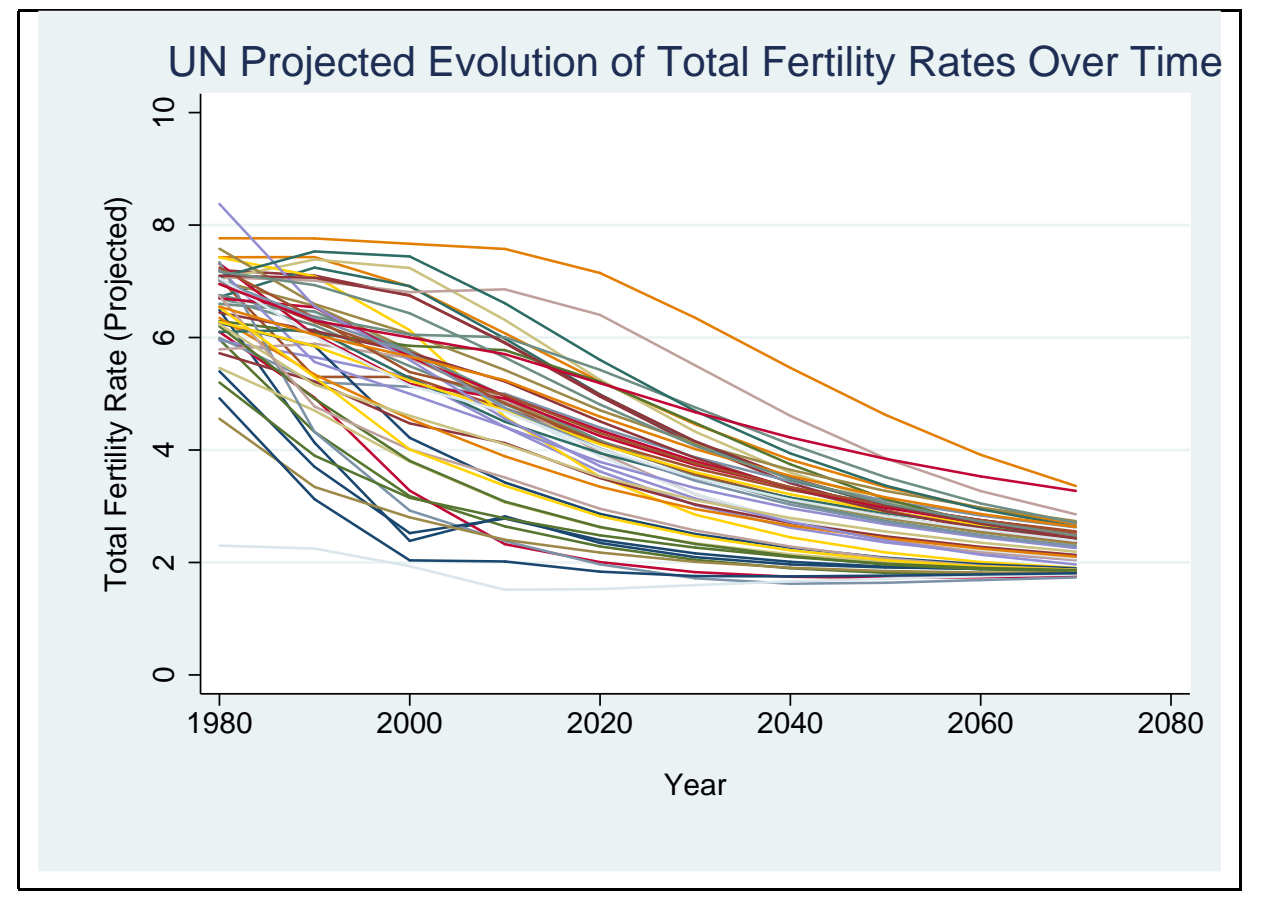

Figure 3: The UN Medium Variant Total Fertility for 48 African Economies. Source: United Nations (2012).

\subsection{The Optimal Choice Problem}

A member $i$ of generation $t$ maximizes his/her utility - equation (5) - subject to the budget constraint equation (6) - , taking factor prices and $\pi^{s}$ and $\pi^{u}$ as given. As shown in Mountford and Rapoport (2011) the first order conditions for this problem define a factor supply schedule for skilled and unskilled labor as a function of the relative wage. The factor demand equation can be derived from the labor market equilibrium equation - equation (3) - and equilibrium is where factor demands and supplies are equal.

Total fertility, $n_{t}$ is also determined in equilibrium and is related to the total time devoted to fertility, the relative costs of rearing skilled and unskilled children and the equilibrium proportions of skilled, $n_{t}^{H} / n_{t}$, and unskilled children, $n_{t}^{L} / n_{t}$, by the following equation,

$$
n_{t}=\frac{1-\theta}{\tau^{s}\left(n_{t}^{H} / n_{t}\right)+\tau^{u}\left(n_{t}^{L} / n_{t}\right)}
$$

\section{Baseline Scenario}

We calibrate the above model using publicly available data on emigration rates, education levels, population and fertility. ${ }^{1}$ We briefly detail below the data

\footnotetext{
${ }^{1}$ The two period overlapping generations framework is a simplifying abstraction which allows for a tractable analysis of the theoretical model. However an implication of this is that
} 
sources used and the assumptions underlying the calibration choices. Our baseline scenario is designed to broadly match the medium-variant UN Population Projections for Africa (United Nations, 2012). We plot the projected fertility (TFR) for African countries in Figure 3, which shows that a crucial underlying assumption in these projections is that in the long-run, the population of each country will be stable. Thus, as we see from the Figure 3, fertility for each country is projected to quickly converge to a level of close to 2 in just a few decades.

Figure 4 shows the UN Projected Population for Africa under the three main variants: high, medium and low-fertility. The medium fertility assumption, which will be used as a benchmark throughout this paper, is the best prediction, as they put it, based on probabilistic scenarios using updated demographic data (the high and low-fertility scenarios, on the other hand, illustrate the robustness of the projection to adding or subtracting half-a-child to the medium-variant scenario).

The main motivation for our study is to show how economic forces may influence the fertility and, ultimately, the population projections for Africa. In particular, we want to investigate whether migration policies may impact the demographic evolution of the African continent since, as demonstrated in our theoretical model, emigration propensities (and differential emigration propensities at different education levels) may affect the quality-quantity tradeoff for children.

\subsection{Data}

Population and fertility data come from the UN Population Division (UN, 2013). Education data comes from Barro and Lee (2013) which provide data for the share of males aged 25 and more with tertiary, secondary and primary education. ${ }^{2}$ Our preferred definition of skilled agents is for those who have completed tertiary education. For missing observations we impute values using an OLS regression with per capita GDP, infant mortality and total fertility rates as regressors.

Emigration data comes from Bruecker, Capuano and Marfouk (2013), who recently collected panel data on immigration stocks disaggregated by country of origin and level of education for 20 OECD receiving countries. The Bruecker et al.

additional assumptions have to be made concerning the mapping of the empirical data into the two period generational framework. An interesting direction of future study would be to extend the analysis to a multiperiod overlapping generation model along the lines of Song, Storesletten, Wang and Zilibotti (2012) where agents live for up to J periods and maximize a utility function given by $\sum_{j=0}^{J} s^{j} \beta^{j} u\left(c_{t+j}, d_{t+j}\right)$ where $s^{j}$ is the probability of surviving until period $\mathrm{J}, \beta$ is the discount factor with $u\left(c_{t+j}, d_{t+j}\right)$ defined as above. This would allow the model to use the five yearly age specific fertility and mortality data from the United Nations Population division, see http://esa.un.org/unpd/wpp/Excel-Data/population.htm. However such analysis is beyond the scope of the present paper.

${ }^{2}$ We use male data for reasons of data availability. 


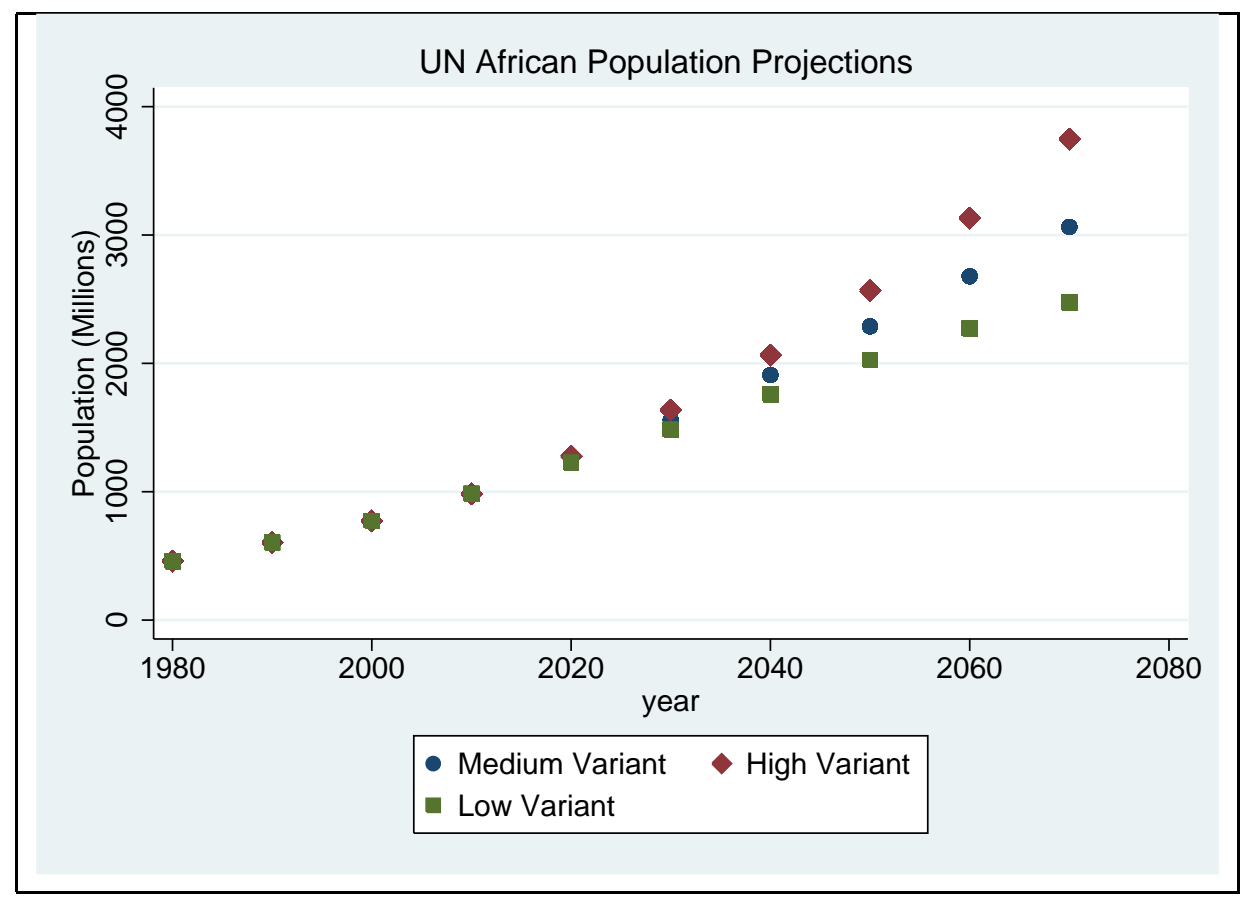

Figure 4: The UN High Medium and Low Variant Projections for the growth of African Population. Source:United Nations (2012).

(2013) dataset provides seven observations between 1980 and 2010 for bilateral immigrant stocks, broken down by gender and level of education for up to 195 origin countries, and it builds upon the methodology proposed by Docquier and Marfouk (2005), Beine, Docquier and Rapoport (2007), Docquier, Lowell and Marfouk (2009) and Defoort (2008). We use the bilateral data and then reaggregate by origin country to compute emigration stocks and rates by education level for all African countries. Note therefore that our emigration variables are intended to proxy for emigration from Africa to the OECD only (i.e., we exclude intra-African and other South-South migration). The data sets provide sufficient data for 48 African economies. ${ }^{3}$ For calculating total African figures we take account of missing countries observations by scaling up the total from our 48 economies using a scale factor that matches the total African population for 2010 data.

Figure 5 shows the evolution in these data of mean education and migration

\footnotetext{
${ }^{3}$ The countries in the dataset are: Benin, Botswana, Burkina Faso, Burundi, Cameroon, Cape Verde, Central African Republic, Chad, Comoros, Congo, Côte d'Ivoire, Democratic Republic of Congo, Djibouti, Egypt, Equatorial Guinea, Ethiopia, Eritrea, Gabon, Gambia, Ghana, Guinea, Guinea-Bissau, Kenya, Lesotho, Liberia, Madagascar, Malawi, Mali, Mauritania, Mauritius, Morocco, Mozambique, Namibia, Niger, Nigeria, Rwanda, Sao Tome and Principe, Senegal, Sierra Leone, Somalia, South Africa, Swaziland, Togo, Tunisia, Uganda, Tanzania, Zambia, Zimbabwe.
} 


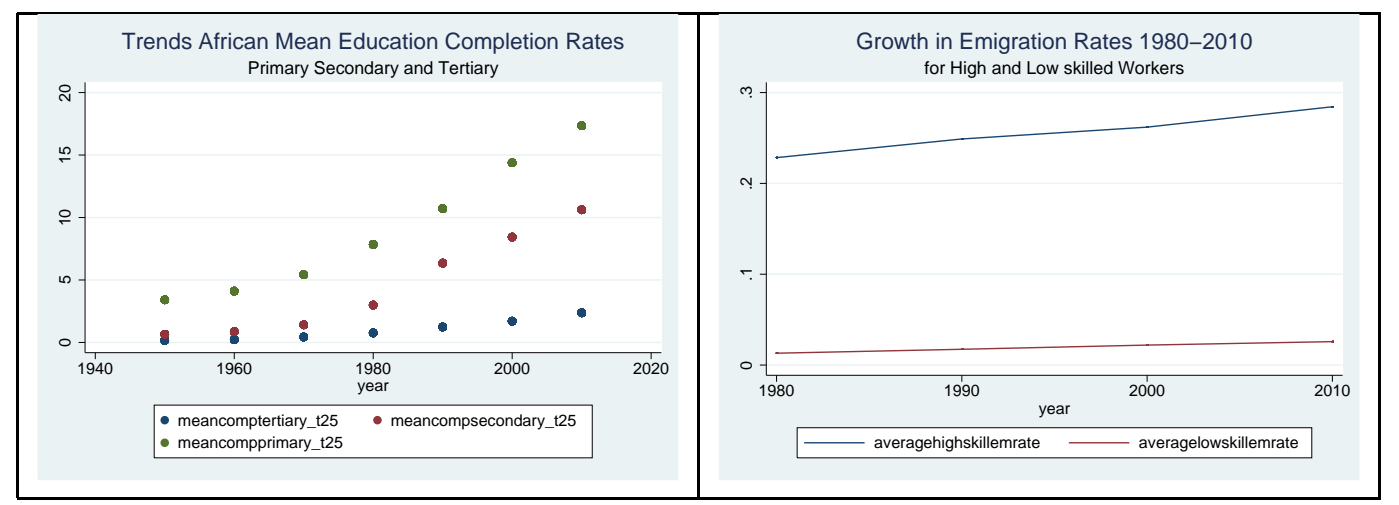

Figure 5: The Evolution of Mean Migration Rates and Education Levels in Africa

rates in Africa over recent decades. The first panel shows how education completion levels have risen through time in all education categories. The second panel shows that migration rates have also been growing through time for both low skilled and high skilled migrants but that the migration rates for highly skilled workers has been rising by more. This fact together with the rising share of highly skilled workers in the labor force implies that the proportion of migrants in the population has also been rising.

\subsection{Calibration}

We choose parameters in our model to match the UN projected population growth medium variant by year 2030. More precisely, we make the following choices. We follow Delogu et al. (2013) in setting the time-cost of raising an uneducated child, $\tau^{u}$, to be 0.0231 (or 3/130) in year 2000. Likewise, following Delogu et al. (2013), we model the cost of uneducated children as increasing over time so that in our case it equals 0.0312 in 2010, 0.0396 and 0.0594 in 2050. This increase represents inter alia the declining opportunity for children to work due to, e.g., greater minimum schooling obligations. Similarly, $\tau^{s}$ is calibrated to decline over time by $40 \%$ by 2030 and by a further $20 \%$ by 2050 . This reflects inter alia the fact that the cost of raising educated children (in time-equivalent units) is declining due to projected increased public spending on education. The initial level of $\tau^{s}$ is calculated using equation (8) with the assumption that total education costs are proportional to our measure of skilled workers. Given this, we then calibrate the total time devoted to child rearing in each country so as to match the rate of population growth in that country projected in the medium-variant of the UN Population Projections in 2030. For this baseline scenario, we calibrate TFP in 2000 by the formula in equation (1) above and assume that the TFP growth of African countries is $2 \%$ above US TFP growth (i.e., there is some element of 


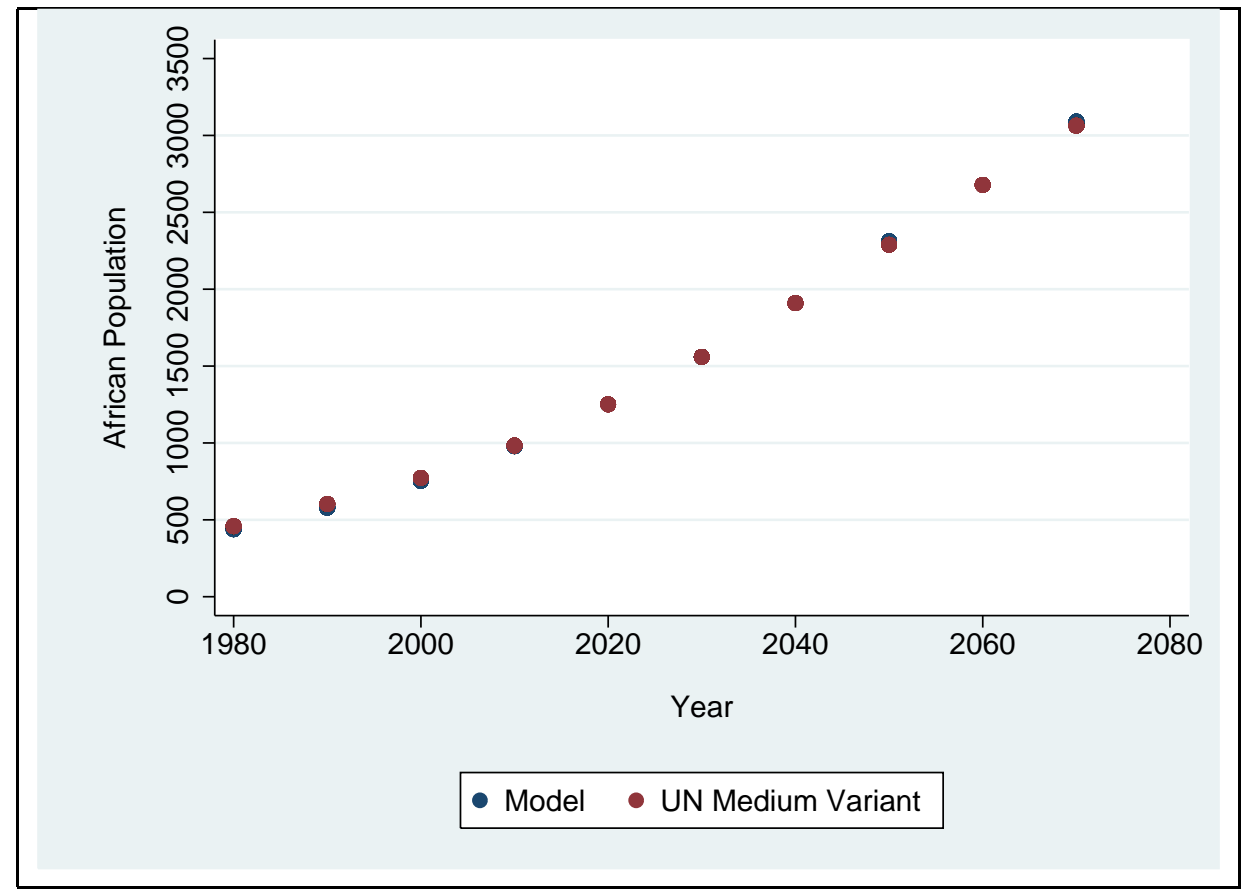

Figure 6: The Evolution of Total African Population in the Baseline Scenario and the UN medium variant

catching-up, again as in Delogu et al. (2013)). Finally, emigration rates of both high- and low-skill workers are as given by the 2010 figures in the Bruecker et al. (2013) data set. We assume that the production function is time invariant and the same in all countries and so different per capita output is caused by differences in productivity and in factor supplies. Equipped with these parameters for all 48 countries we calculate the equilibrium $a^{\star}$ for each country and at each time period as described in Section 2, which determines the model's predicted share of educated in the population and, thereby, fertility. We assume the distribution of abilities is truncated normal with a mean of 0.95 and a variance of 1 .

We display the calibration of our baseline scenario in Figures 6 and 7. In Figure 6 we plot the model's projected total African population growth with that of the UN medium-variant scenario. This shows that we have chosen our parameters so that the model matches very closely on aggregate the UN Medium variant. In Figure 7 we plot the model's projected population growth rate for each of the 48 countries alongside the same graph for the UN medium variant. While for individual countries the goodness of fit varies (see, e.g., Figure 9 below), Figure 7 shows that the general shape is very similar, with both the model and the UN medium-variant scenario's baselines having the characteristic that all economies are tending towards a stable population in the long run. 


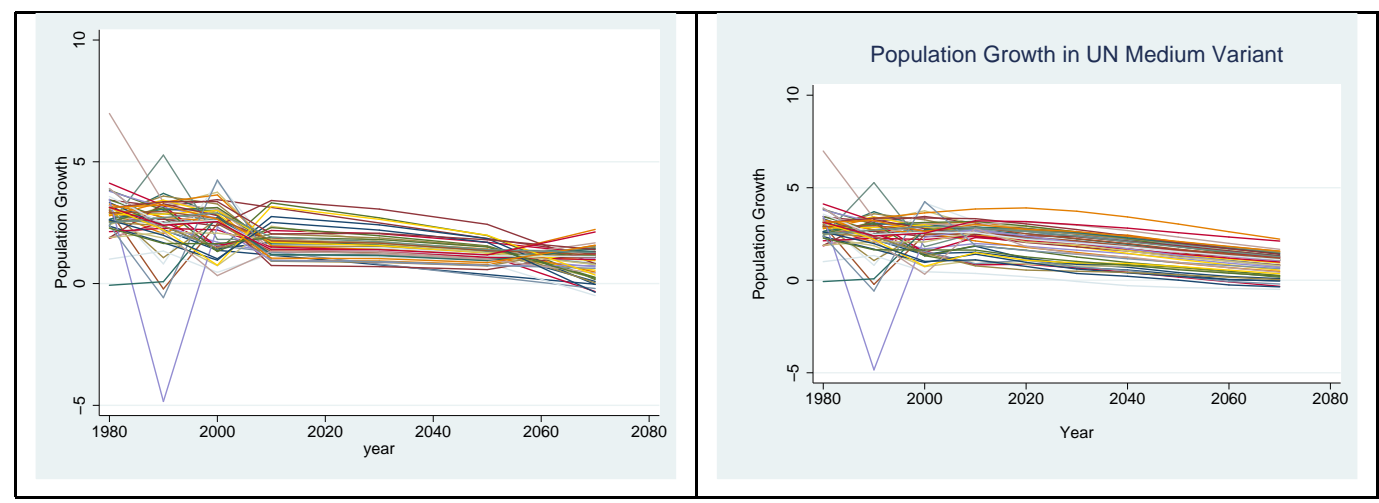

Figure 7: The Population growth rate for 48 African Economies under the Baseline scenario (left) and the UN Medium Variant (right)

\section{Alternative scenarios based on different im- migration policies}

To investigate the role of immigration policies in affecting demography in Africa, we examine three alternative scenarios: a scenario where emigration becomes more skill biased; a scenario where emigration becomes more unskilled biased; and a scenario where emigration is reduced. Clearly there are many possible scenarios that we could simulate using the model e.g. different policies for different regions, different colonial links, or different migration histories, but we focus on these three alternative scenarios to illustrate the main economic forces at play in the model. In order to illustrate graphically the differences between the scenarios we assume large differences in emigration rates across scenarios e.g. in the high skill emigration biased scenario we assume each country's skilled emigration rate is $50 \%$ higher than in 2000 and the low skilled emigration rate is $50 \%$ lower. This leads to differences across the scenarios that can be nicely illustrated in Figure 8. In section 4.4 below we discuss policy scenarios based on the current trends in migration rates and these show the same qualitative responses although smaller in magnitude.

\subsection{A High Skilled Biased - Brain Drain - Scenario}

This can be thought of as the continuation of the recent evolution of immigration policies in OECD countries and the general tendency for them to become increasingly restrictive and at the same time quality-selective, we assume that increased restrictiveness translates into dividing by two the emigration rate for low-skill workers while increased selectivity translates into increasing by a half the emigration rate for high-skill workers. See Mountford and Rapoport (2011) 


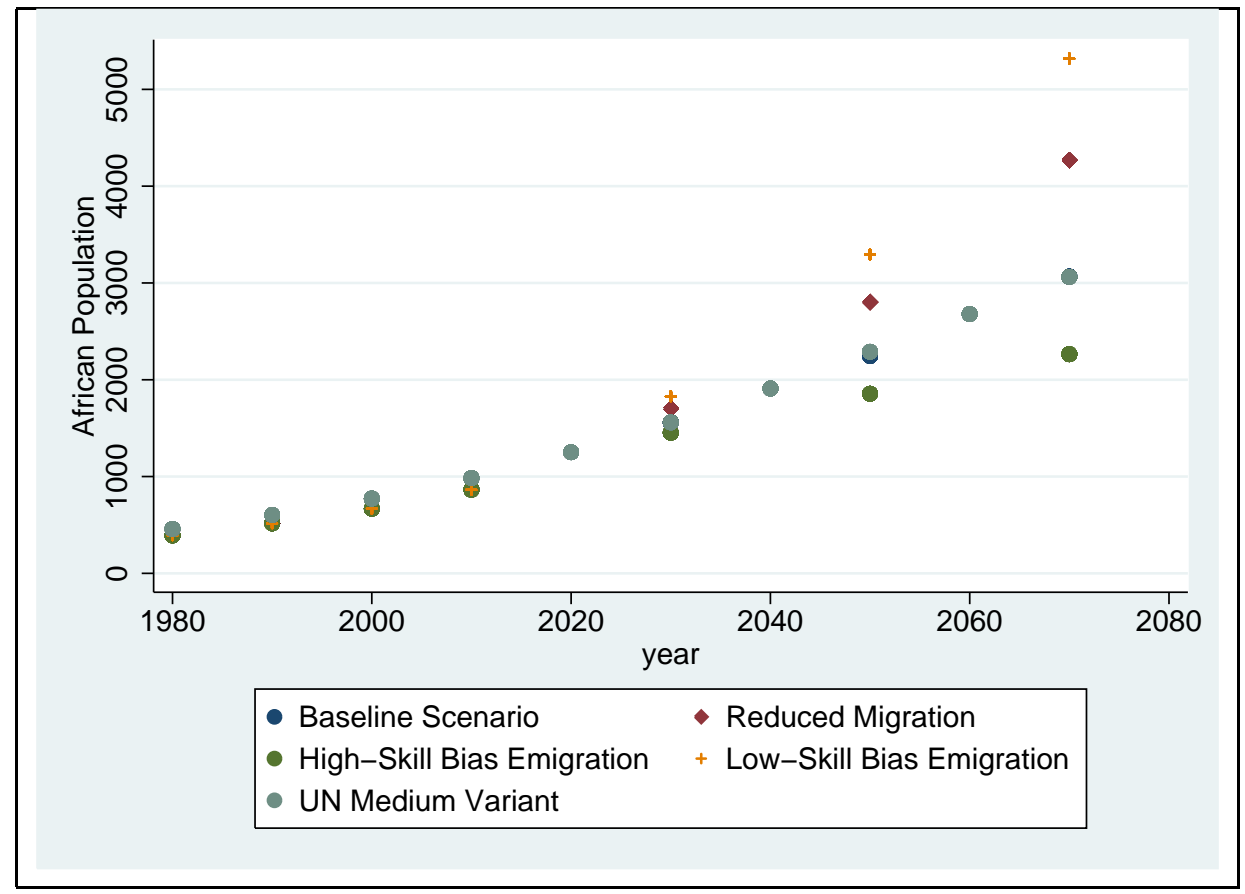

Figure 8: The Evolution of Total African Population Under Alternative Scenarios

for a description of the recent policy changes in OECD economies.

The effect on the population growth in Africa of the skill biased emigration scenario is shown in Figure 8. This shows that this policy has the effect of reducing the rate of population in Africa by nearly 370 million in 2050 compared to the baseline scenario, and by 700 million 2070, which is a similar magnitude as between the medium and low variant's of the UN population projections in Figure 4. The intuition for this result is straightforward. The increased relative probability to emigrate amongst high skilled workers increases their relative expected wage and so induces families in African economies to rear more high skilled offspring which, as high skilled offspring take more parental time and are more costly, implies via the budget constraint that total fertility declines. As time progresses the effect cumulates as a smaller number of offspring imply a smaller number of parents and so on.

Note also that the effect of this scenario is not spread equally across Africa as shown in Figure 9. In an economy with a high rate of emigration, such as Senegal, the effect of alternative scenarios are proportionately greater than in a country with lower rates of emigration, such as for example, Zambia. Differences occur because different countries have different migration rates and also different proportions of educated people in the economy. 


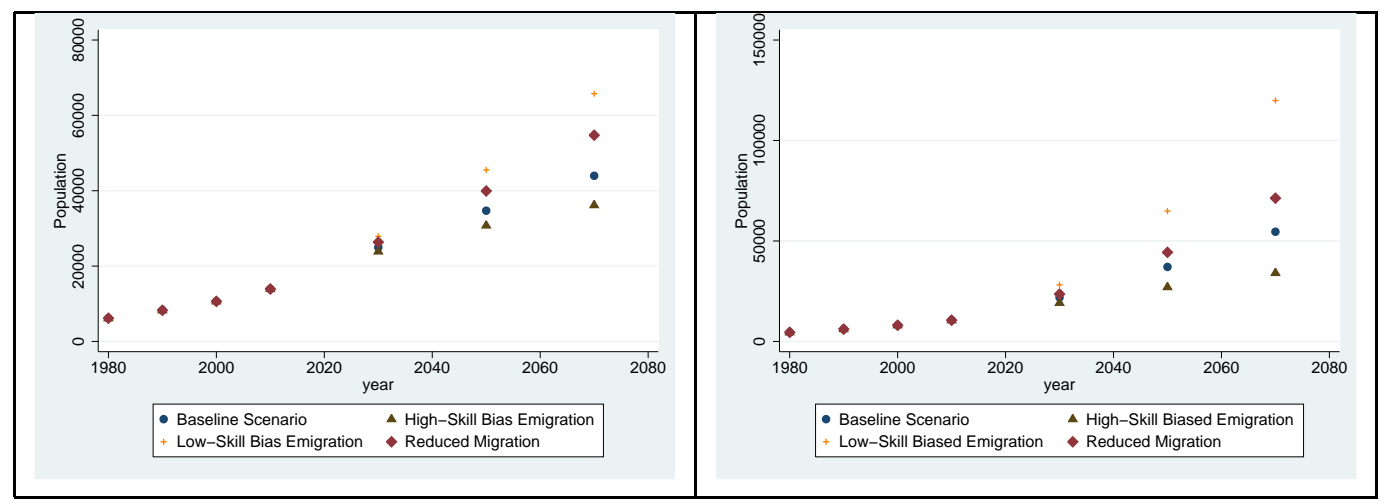

Figure 9: The Evolution of Population in high emigration - Senegal - and lower emigration - Zambia- economies Under Alternative Scenarios

\subsection{A Low Skilled Biased Scenario}

In this scenario we assume by contrast that the high skilled emigration rate in each country is 50\% lower than in 2000 and that the low skilled emigration rate is $50 \%$ higher. This can be thought of as a scenario where globalization, perhaps via the increased bargaining power of multinational corporations has reduced the ability of countries to implement a restrictive immigration policy. As Figure 8 shows that this policy has the effect of increasing the rate of population in Africa by nearly 900 million in 2050 compared to the baseline scenario, which is about twice the order of magnitude as differences between the UN medium and High and Low variants as shown in Fig 4. As already stated, smaller numbers would be obtained for smaller changes in migration rates. Also note that although this scenario is a mirror image of the high-skilled biased emigration in terms of emigration rates its implications for population are not.

\subsection{A Reduced Migration Scenario}

This scenario shows that even a general reduction in migration will affect the rate of population growth. Intuitively this is because the African economies have a lower growth rate and so a lower autarkic demand for skilled agents than developed economies. Hence a move towards autarky has the effect of reducing the incentive of households to have fewer, more costly, skilled offspring rather than larger numbers of unskilled offspring and so projected population is higher than under the baseline scenario although not as high as in the low skilled emigration biased scenario as shown in Figure 8. 
TABLE 1

African Population (in Billions) Under Alternative Scenarios

\begin{tabular}{c|cccc}
\hline \hline Date & $\begin{array}{c}\text { Baseline } \\
\text { Scenario }\end{array}$ & $\begin{array}{c}\text { Continued } \\
\text { Emigration Growth }\end{array}$ & $\begin{array}{c}\text { Skill-Bias } \\
\text { Emigration }\end{array}$ & $\begin{array}{c}\text { Unskilled-Bias } \\
\text { Emigration }\end{array}$ \\
\hline 2030 & 1.56 & 1.56 & 1.53 & 1.60 \\
2050 & 2.25 & 2.22 & 2.08 & 2.43 \\
& & & & \\
2070 & 3.06 & 3.01 & 2.62 & 3.55 \\
\hline \hline
\end{tabular}

This table shows the effect of different migration scenarios on the evolution of African population. The different scenarios are the baseline scenario, the continued emigration growth scenario where the high skilled emigration and low skilled emigration rate continues to grow at their historical averages and the high (low) skilled emigration bias scenario where only the skilled (unskilled) emigration rate continues to grow.

\subsection{Policy Scenarios Based on Current Migration Trends}

The scenarios above were designed to highlight the potential importance of economic forces rather than describe reality. In this section we use historical emigration rates to calibrate the scenarios. The results which are displayed in Table 4.3, while smaller, have the same qualitative features as the scenarios above.

The historical rates of emigration growth are shown in Figure 5. This shows that within our sample the high skilled emigration rate has increased by about $7 \%$ by decade and the low skilled emigration rate by $26 \%$ a decade, albeit from a low base. We use these rates when calculating our scenarios. In our "Continued Emigration Growth Scenario" we assume that the emigration rates of each type of labor continues to grow at these historical rates. In the "Skill-Bias Emigration Growth Scenario" we assume that the emigration rates of skilled labor continues to grow at its historical rate but that unskilled emigration remains at its 2010 level. In the "Unskilled-Bias Emigration Growth Scenario" we assume that the emigration rates of unskilled labor continues to grow at its historical rate but that skilled emigration remains at its 2010 level. The results show that as above a skilled bias growth of emigration would lead to a reduction in African population by about $7.5 \%$ relative to baseline scenario in 2050 and $14 \%$ in 2070 . Conversely an unskilled bias growth of emigration would lead to an increase in African population by about $8 \%$ relative to baseline scenario in 2050 and $16 \%$ in 2070 . If both unskilled and skilled labor continue to grow at their historical rates then these opposing effects offset each other so that the population relative to the baseline scenario only falls by $1.6 \%$. 


\section{Conclusion}

As Secretary of State John Kerry speech to the African Union makes clear, the evolution of world inequality depends significantly on the evolution of fertility, human capital accumulation and population growth rates in Africa. This paper has applied a microfounded model of education and fertility choice to recent data on fertility, human capital accumulation and migration propensities in African economies. It has shown how economic forces which affect the relative returns to skilled and unskilled labor - in particular migration propensities - can have significant effects on the evolution of African economies and thereby on the world distribution of income. The model we have presented here is highly stylised and so its precise numbers should not be taken too literally. However what the model has shown is that there are good reasons to believe that current trends in the African economy imply that migration policies may have a large leverage on the evolution of African economies. In particular skilled biased migration opportunities may significantly increase educational demand and reduce population growth. This is therefore a very promising area for further research. 


\section{REFERENCES}

Barro, R. and J.W. Lee (2013): A new data set of educational attainment in the world, 1950-2010, Journal of Development Economics, 104: 184-198

Beine, M., F. Docquier and H. Rapoport (2007): Measuring international skilled migration: a new database controlling for age of entry, World Bank Economic Review, 21, 2: 249-54.

Beine, M., F. Docquier, and M. Schiff (2013). International Migration, Transfer of Norms and Home Country Fertility, Canadian Journal of Economics, 46(4), 1406-1430.

Bertoli, S., and F. Marchetta (forthcoming). Bringing It All Back Home: Return Migration and Fertility Choices, World Development.

Brucker H., S. Capuano and A. Marfouk (2013): Education, gender and international migration: insights from a panel-dataset 1980-2010, mimeo.

Daudin, G., R. Franck and H. Rapoport (2013): The cultural diffusion of the fertility transition: evidence from internal migration in 19th century France, Mimeo., Paris School of Economics.

Defoort, C. (2008): Tendances de long terme des migrations internationales : Analyse à partir des 6 principaux pays receveurs, Population, 63, $2: 285-318$.

Delogu, M., F. Docquier and J. Machado (2013): The dynamic implications of liberalizing global migration, Working Paper, Catholic University of Louvain.

Docquier, F., B. L. Lowell and A. Marfouk (2009): A gendered assessment of the brain drain, Population and Development Review, 35, 2: 297-321.

Docquier, F. and A. Marfouk (2006): International migration by education attainment, 1990-2000; in C. Ozden \& M. Schiff (eds): International Migration, Brain Drain and Remittances, New York: McMillan and Palgrave. Chapter 5, pp. 151-99.

Fargues, P. (2007). The Demographic Benefit of International Migration: a Hypothesis and its Application to Middle Eastern and North African Countries. In:Ozden, C., and M. Schiff (eds.), International Migration, Economic Development and Policy, World Bank: Washington, DC.

Galor, O. (2005): From stagnation to growth: unified growth theory, in Philippe Aghion and Steven N. Durlauf, eds., Handbook of Economic Growth, Vol. 1A, Chapter 4, pp. 171-293.

Galor, O. and O. Moav (2000). "Ability Biased Technological Transition, Wage Inequality and Economic Growth", Quarterly Journal of Economics, 115: 469-498.

Gould, E., O. Moav and B. Weinberg (2001). "Precautionary Demand for Education, Inequality and Technological Progress". Journal of Economic Growth, 6: 285-316.

Kanbur, R. and H. Rapoport (2005): Migration selectivity and the evolution of spatial inequality, Journal of Economic Geography, 5, 1: 43-57.

Katz, E. and H. Rapoport (2005): On human capital formation with exit options, Journal of Population Economics, 18, 2: 267-74.

Mountford, A. (1997): Can a brain drain be good for growth in the source economy?, Journal of Development Economics, 53, 2: 287-303.

Mountford, A. and H. Rapoport (2011): The Brain Drain and the World Distribution of Income, Journal of Development Economics, 95, 1: 4-17.

New York Times (2013a): "Population Growth Forecast From The UN May Be Too High", September 21, 2013. URL:http://www.nytimes.com/2013/09/21/business/unsforecast-of-population-growth-may-be-too-high.html

New York Times (2013b): "China to ease longtime policy of 1-Child limit", November 15, 2013. URL: http://www.nytimes.com/2013/11/16/world/asia/china-to-loosenits-one-child-policy.html

Song, Z., K. Storesletten, Y. Wang and F. Zilibotti (2012): Sharing High Growth Across Generations: Pensions and Demographic Transition in China, UBSCENTER Working Papers 001, UBS International Center of Economics in Society, University of Zurich.

United Nations (2012): World Population Prospects: the 2012 Revision, UN Department of Economic and Social Affairs Population Devision, June. 